\title{
Field experimental study on optimal design of the rotary strip-till tools applied in rice-wheat rotation cropping system
}

\author{
Yanshan Yang ${ }^{1}$, John Fielke ${ }^{2}$, Qishuo Ding ${ }^{1 *}$, Ruiyin $\mathrm{He}^{1}$ \\ (1. College of Engineering, Nanjing Agricultural University, Nanjing 210031, China; \\ 2. School of Engineering, University of South Australia, Mawson Lakes, SA 5095, Australia)
}

\begin{abstract}
The rice-wheat rotation system plays a significant role in Asian agriculture. The introduction of strip-tillage into the rice-wheat system for wheat planting offers a way to use conservation tillage practices to improve the seedbed quality, retain residue between rows and reduce energy input. A field experiment was conducted using an in-situ test rig. Three types of blade (bent C, straight and hoe) were evaluated in four tool configurations at four rotary speeds (180 r/min, $280 \mathrm{r} / \mathrm{min}$, $380 \mathrm{r} / \mathrm{min}$ and $510 \mathrm{r} / \mathrm{min}$ ) in a paddy soil. Furrow shape parameters, tillage-induced soil structures and energy consumption were assessed. Results showed that the straight blade configuration failed to create a continuous furrow at either $180 \mathrm{r} / \mathrm{min}$ or $510 \mathrm{r} / \mathrm{min}$. The bent $\mathrm{C}$ blade configuration produced a uniform furrow profile but its furrow backfill was poor and unsuitable for seeding. The hoe blade configuration cut a continuous furrow and better tillage-induced soil structure, but it produced a much wider and non-uniform furrow shape. The mixed blade configuration (central hoe blades with two straight blades aside) provided a uniform furrow with good backfill and fine tilth by utilizing both the cutting effect of straight blades on the furrow boundaries and tensile fracturing of the furrow soil by the hoe blades. The torque of the mixed blade configuration was comparable with the bent $\mathrm{C}$ blade but was less than the hoe blades. Hence, a mixed blade configuration was recommended for rotary strip-tillage seeding using in rice-wheat system.
\end{abstract}

Keywords: strip tillage, rotary strip-till tool, blade configuration, furrow quality, tilth, torque, rice-wheat rotation system DOI: $10.25165 /$ j.ijabe.20181102.3347

Citation: Yang Y S, Fielke J, Ding Q S, He R Y. Field experimental study on optimal design of the rotary strip-till tools applied in rice-wheat rotation cropping system. Int J Agric \& Biol Eng, 2018; 11(2): 88-94.

\section{Introduction}

The rice-wheat rotation in Asian countries occupies 24 million hectares and is critically important for the region's food security, providing grain supply for about $8 \%$ of the world's population ${ }^{[1-3]}$. This rotation is characterized as an intensive farming system with at least two crops grown per year. Currently the rice-wheat rotation relies on intensive cultivation and many external inputs. Degraded soil quality is alleged to be the major cause for the slowdown of its productivity growth ${ }^{[4]}$. Damaged soil structure, declining soil organic matter content and impaired soil fertility are limiting the yield and threatening the sustainability of this system $^{[5,6]}$.

In the last decades the introduction of conservation tillage (CT) into the annual rice-wheat rotation for wheat planting has proved the benefits of reduced energy and resource inputs and has stimulated system output and profitability ${ }^{[3,4,6-9]}$. One of the CT methods is to use strip-tillage. Strip tillage can be achieved with a rotary tiller to cut a 50-200 $\mathrm{mm}$ seed furrow in the soil for use as a seedbed. By tilling seed furrows, the area of soil disturbed is minimized, leaving the inter-row areas undisturbed and covered with crop residue. Rotary strip-tillage also offers a solution to improve the seedbed environment in the poorly drained paddy

\section{Received date: 2017-03-14 Accepted date: 2017-11-30}

Biographies: Yanshan Yang, $\mathrm{PhD}$, research interests: soil and tillage, Email: yang_yan_shan@163.com; John Fielke, PhD, Professor, research interests: agricultural machinery design, Email: John.Fielke@unisa.edu.au; Ruiyin He, $\mathrm{PhD}$, Professor, research interests: seeding and tillage machinery design, Email: ryhe@njau.edu.cn.

*Corresponding Author: Qishuo Ding, PhD, Professor, research interests: soil and tillage. No. 40 Dianjiangtai Road, Pukou District, Nanjing 210031, China. Tel: +86-15850723939, Email: qsding@njau.edu.cn. soils ${ }^{[10]}$ mainly through improved infiltration. An one-pass operation combining strip-tillage and seeding will also reduce the time between harvesting of one crop and planting of the next, thus giving another driver for farmers to accelerate the adoption of CT into Asian rice-wheat system. As most farmers in the region already possess a rotary tiller, converting it to a rotary strip tiller and seeder is an easy task. It can be done in either small or large scale farms using 2 or 4 wheeled tractors of any size.

The desired outcome from strip-tillage is the finished furrows with regular shapes (straight furrow sidewall and leveled furrow bottom), being filled with fine tilth and having minimal crop residue incorporated. These requirements allow for good seed-soil contact for seed germination, crop root growth and soil moisture retention ${ }^{[11-15]}$. Several studies in soil bins were conducted to improve the cultivation quality of rotary strip-tillage by optimizing tool geometry and the operating parameters, with an aim of cutting the trash cover and retaining the loosened soil in the furrow $^{[13,16-18]}$. A down-cut process and four rotary blades around the periphery were recommended using in sandy loam soil condition by Lee et al. ${ }^{[16]}$. Matin et al. ${ }^{[13]}$ evaluated the performance of the bent $\mathrm{C}$ blade for strip-tillage, showing that too much soil was carried out of the furrow. They thus recommended using a straight blade for strip-tillage in dry soil conditions, as it could leave the finished furrow filled with loose tilth suitable for a seedbed. However these related recommendations have not yet been evaluated in actual field conditions. Soil bin studies were justified with better control of soil physical parameters and machine operating variables, as well as the possibility for repeated tests over short periods without weather constraints ${ }^{[19]}$. The soil used in a soil bin is structureless due to the frequent disturbance by tillage and compaction between tests for soil preparation ${ }^{[20]}$. In contrast, field soil structure is a combined result from soil genesis, 
weather conditions and the cropping system, and as thus cannot be readily reproduced in a soil bin. The properties of remolded soil are different from that in the field ${ }^{[21]}$. Therefore, verification of the conclusions from soil bin experiments with actual field tests is necessary ${ }^{[2]}$. The undertaking of field evaluations and demonstrations of the performance of rotary strip-tillage tools is also important for promoting CT to the rice-wheat rotation.

In order to achieve a finer tilth and a regular furrow shape, researchers have recommended using higher rotor speeds for strip-tillage ${ }^{[13,16]}$. However, a higher rotary speed results into increased stress on the soil ${ }^{[23]}$, leading to a negative effect on soil structure. Increased smearing and compaction may damage soil porosity, impede gas/water movement and root penetration ${ }^{[18]}$. For simple tillage tools, soil failure patterns have been well approved as key contributing factors for fine tilth ${ }^{[24,25]}$. Therefore, despite the higher rotor speeds recommended, inducing a proper soil failure pattern for strip-tillage could be an effective measure for improved soil structures, especially in paddy soil conditions.

Apart from the established standard bent $\mathrm{C}$ blades, the hoe blade is a recently introduced tool by the industry for reduced tillage. Farmers' preference on the hoe blade was due to its effectiveness in working the hard soils and producing better soil structures. Lee et al. ${ }^{[16]}$ proposed a strip-tillage tool design using two flat soil-cutting disc blades to enhance furrow formation. But the disc blades were found to have considerably increased the torque requirement. Matin et al. ${ }^{[13]}$ found that the use of straight blades assisted furrow uniformity and improved backfill by intercepting the loosened soil as it moves laterally. In this paper, the evolving technology inspired the design of a mixed blade configuration which combines the beneficial performances of different tools, i.e. a central hoe blade for effective soil loosening and a straight blade on the side to cut and retain a rectangular shaped furrow filled with tilth. Therefore, this work evaluated the performances of a number of blade combinations with respect to energy use, furrow shape, furrow backfill and tilth quality. The aim was to find a suitable strip-tillage tool design and its working parameters that could be recommended for use with rotary strip-tillage for sowing wheat in a rice-wheat rotation.

\section{Materials and methods}

\subsection{Rotary tiller blades and tool configurations}

Three types of rotary tiller blades (bent C, straight and hoe) were used for the experiment (Figure 1). The three types of blades were assembled in four configurations, the first three of which used a single type of blades (Figure 2 A-C). The fourth configuration used a mixed blades assemblage, with two hoe blades mid-positioned and a straight blade attached on each side (Figure 2 D). The blades were fitted onto a shaft as shown in Figure 2. All configurations had a common external diameter of $455 \mathrm{~mm}$.

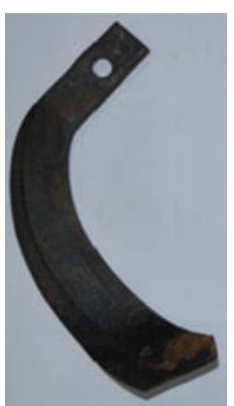

a. Bent C blade

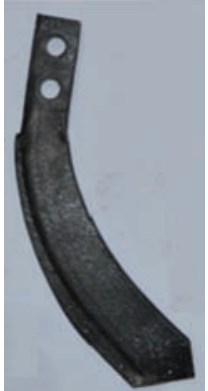

b. Straight blade

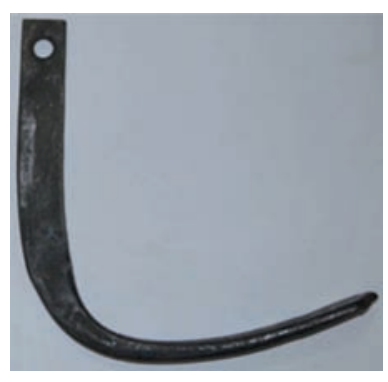

c. Hoe blade
Figure 1 Rotary tiller blades

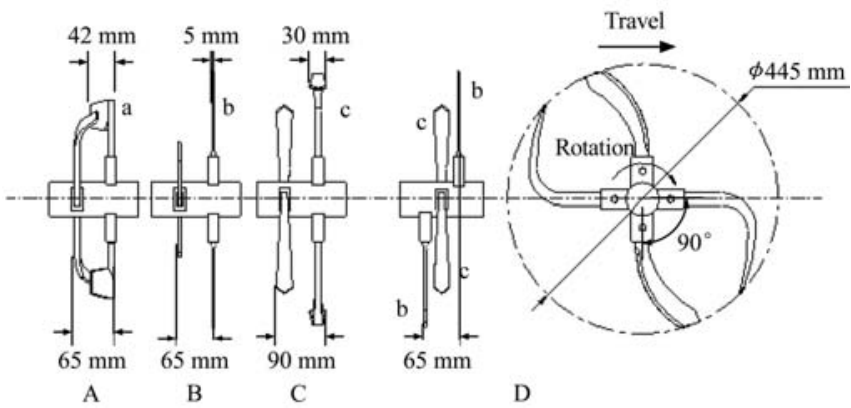

Figure 2 Rotary blade configurations on shaft

\subsection{Development of a rig for in-situ field test}

A multi-functional test rig for in-situ tillage research was developed at Nanjing Agricultural University, China (Figure 3a). The test rig was of stand-alone construction, spanning $8 \mathrm{~m}$ long and $1.8 \mathrm{~m}$ wide and equipped with an independent power transmission system, a control system and a multi-functional carriage. A $4 \mathrm{~kW}$ electric motor was used for traction. The trailed carriage ran on twin rails with a length of $6 \mathrm{~m}$ and the speed was adjustable at $0.1-1 \mathrm{~m} / \mathrm{s}$. The rotary tiller shaft was powered by a $7.5 \mathrm{~kW}$ electric motor mounted on the carriage (Figure $3 b$ ). The operating depth was controlled by a power screw driven by an electric motor. The speed of the rotary tiller was adjustable from $0-600 \mathrm{r} / \mathrm{min}$. The test rig was supported on four pillars, each with a $0.75 \mathrm{~kW}$ electric motor for raising/lowering the whole rig. Electric power was supplied by a $13.5 \mathrm{~kW}$ generator. A torque sensor was attached to the driving shaft of the rotary tiller. The output of the torque sensor was transferred to a computerized data collecting system, with a sampling rate of $500 \mathrm{~Hz}$.

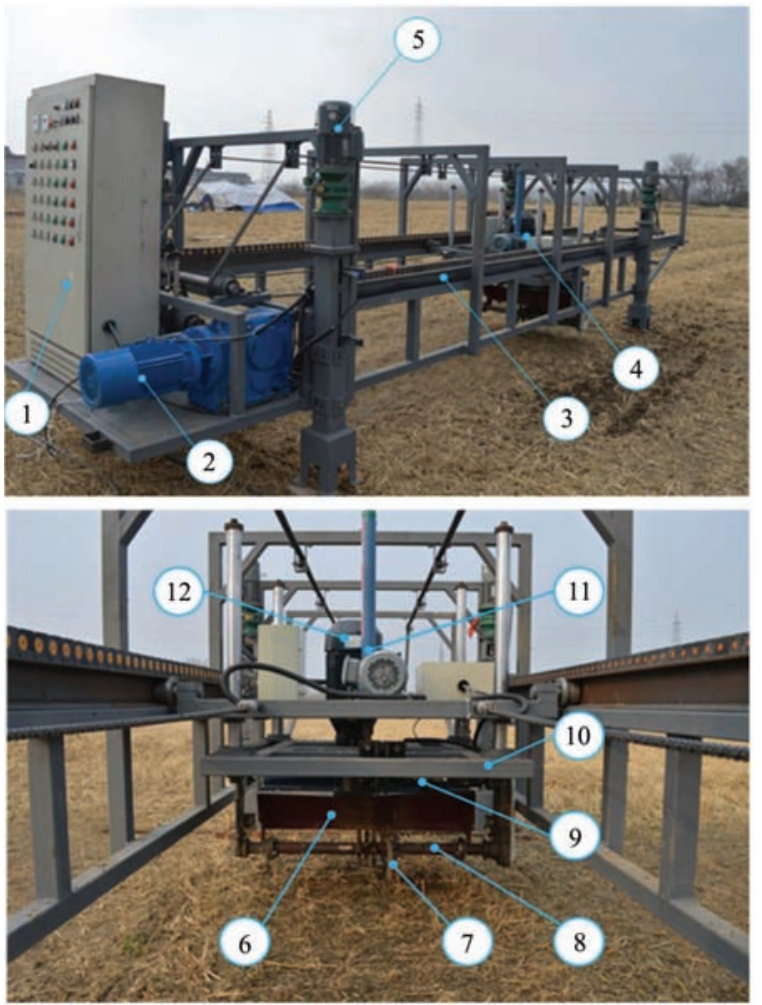

1. Control panel 2. Traction motor 3. Guide rail 4. Carriage 5. Raise/ lower motor 6 . Shield 7. Rotary blade 8 . Shaft 9. Torque sensor 10. Tiller frame 11. Power screw and motor 12. Rotary tiller motor

Figure 3 Overview of the in-situ field test rig

\subsection{Field experiment}

The field experiment was conducted on December 9-10, 2015 in Babaiqiao, Nanjing, Jiangsu Province, China, during the 
turn-around period from rice to wheat. The experimental site had a long history of rice-wheat rotation. Soil texture was determined by the Bouyoucos Hydrometer Method ${ }^{[26]}$, soil moisture content and dry bulk density by the gravimetric method, and shear strength properties using a direct shear box apparatus. The cone index (penetration resistance) was measured with a cone penetrometer
(TJSD-750, Zhejiang Top Instrument Co. Ltd, China) which had a $12 \mathrm{~mm}$ base diameter and $30^{\circ}$ cone. The soil was composed of $35.6 \%$ clay, $40.4 \%$ silt and $24.1 \%$ sand and was classified as a clay loam. As the tillage was to be undertaken to a $5 \mathrm{~cm}$ depth the soil physical properties of the top $10 \mathrm{~cm}$ layer were measured and were shown in Table 1.

Table 1 Physical and mechanical properties of paddy soil

\begin{tabular}{|c|c|c|c|c|c|c|c|}
\hline Depth/cm & Water content $/ \%$ & Dry bulk density $/ \mathrm{g} \cdot \mathrm{cm}^{-3}$ & Cohesion $/ \mathrm{kPa}$ & Internal friction angle $/\left({ }^{\circ}\right)$ & Cone index $/ \mathrm{kPa}$ & Plastic limit $/ \%$ & Field capacity $/ \%$ \\
\hline $0-10$ & 31.8 & 1.25 & 30.91 & 13.1 & 348 & 25.2 & 40.6 \\
\hline
\end{tabular}

\subsection{Experimental methods}

\subsubsection{Rotary tillage}

The four strip-till blade configurations were tested at four rotary speeds of $180 \mathrm{r} / \mathrm{min}, 280 \mathrm{r} / \mathrm{min}, 380 \mathrm{r} / \mathrm{min}$ and $510 \mathrm{r} / \mathrm{min}$. The blades were operated using a down cut, as proposed by Lee et al. ${ }^{[16]}$. Tillage depth was set to a typical sowing depth of $5 \mathrm{~cm}$ and the forward speed was adjusted to $0.3 \mathrm{~m} / \mathrm{s}$. Tillage depth was calibrated before each test by making a trial run where the resulted furrow depth was checked. Twelve field plots were used in this experiment (four tool configurations with 3 replications) over an area of $700 \mathrm{~m}^{2}$ selected for its homogenous soil conditions. Each plot was $8 \mathrm{~m}$ long and $4 \mathrm{~m}$ wide. Within each plot the four rotary speeds were evaluated for a given blade configuration. Each test provided a stable $5 \mathrm{~m}$ long furrow opening. All the testing was undertaken in a same day.

After testing, the tilled soil was left to be air-dried for 1 day for ease of sample collection and handling. For sampling, a $1 \mathrm{~m}$ long furrow was randomly selected and marked with lines for analysis. The soil thrown out of the furrow was carefully cleaned away before collecting the loose soil remaining in the furrow. It was brought back to the lab for sieving analysis.

2.4.2 Furrow shape measurement

After cleaning the furrow, the boundaries and bottom condition were photographed and the furrow shape was recorded using a profile meter as used by Chen et al. ${ }^{[27]}$ Photos were taken and the reading of each probe was later digitized in the lab to reproduce the furrow shapes.

\subsubsection{Soil fragmentation}

The sampled soil was sieved with a nest of sieves with openings of $1 \mathrm{~mm}, 2 \mathrm{~mm}, 4 \mathrm{~mm}, 8 \mathrm{~mm}, 16 \mathrm{~mm}, 32 \mathrm{~mm}$ and $64 \mathrm{~mm}$ and weighed ${ }^{[28,29]}$. Mean Weight Diameter (MWD) was used to evaluate the degree of soil fragmentation induced by the strip-till tools using Equation (1) ${ }^{[30]}$.

$$
M W D=\sum_{R=r \max }^{r \min } W_{R} R
$$

where, $R$ is the sieve size and $W_{R}$ is the weight ratio of the material retained on the sieve of size $R$. A lower MWD means a finer soil tilth.

\subsubsection{Furrow backfill}

Furrow backfill was measured as the gravimetric proportion of loosened soil retained within the furrow after tillage. The sampled soil from $1 \mathrm{~m}$ length of furrow was dried and its mass measured. Corresponding furrow volume was measured using a sand replacement method using a dry sand (particles $<1.0 \mathrm{~mm}$ ) of bulk density $1288 \mathrm{~kg} / \mathrm{m}^{3}$ and a thin plastic cloth $(0.2 \mathrm{~mm}$ thick $)$. The percentage furrow backfill can be calculated as ${ }^{[13]}$ :

$$
F_{b}=\frac{W}{v \cdot \rho} \times 100 \%
$$

where, $F_{b}$ is furrow backfill, $\% ; W$ is total dry mass of soil remaining in the furrow, $\mathrm{kg} ; V$ is volume of the tilled furrow, $\mathrm{m}^{3}$; $\rho$ is the bulk density of the untilled soil, $\mathrm{kg} / \mathrm{m}^{3}$.

\subsubsection{Specific work}

Specific work was calculated as energy per unit volume of furrow using the formula from ${ }^{[31]}$, as shown in Equation (3).

$$
S W=\frac{M \cdot n \cdot \pi}{30 v_{f} \cdot B \cdot a} \times 100 \%
$$

where, $S W$ is the specific work requirement, $\mathrm{J} / \mathrm{m}^{3} ; M$ is torque, $\mathrm{N} \cdot \mathrm{m}$; $\mathrm{n}$ is rotor speed, $\mathrm{r} / \mathrm{min} ; v_{f}$ is driving speed, $\mathrm{m} / \mathrm{s} ; B$ is working width, $\mathrm{m} ; a$ is working depth, $\mathrm{m}$.

\section{Results}

\subsection{Furrow shape}

The cross sectional views of furrow shapes induced by different blade configurations and speeds were shown in Figure 4. Images of the furrows after emptying of loosened soil were shown in Figure 5 for $180 \mathrm{r} / \mathrm{min}$ and Figure 6 for $510 \mathrm{r} / \mathrm{min}$. The straight blades failed to create a continuous furrow at either $180 \mathrm{r} / \mathrm{min}$ or $510 \mathrm{r} / \mathrm{min}$, as shown in the top views of Figure $5 \mathrm{~b}$ and Figure $6 \mathrm{~b}$, respectively. Fully formed furrows were produced by the other three blade configurations at all speeds.

\subsection{Soil fragmentation and tilth}

The amount of soil fragmentation and quality of the tilth was measured as MWD with a comparison of the test results shown in Figure 7. For all tests, the MWD reduced with increasing speed. As a continuous furrow was not produced for the straight blade configuration at either 180 or $510 \mathrm{r} / \mathrm{min}$, no data was supplied for those conditions. The MWD produced by the straight blade at $280 \mathrm{r} / \mathrm{min}$ and $380 \mathrm{r} / \mathrm{min}$ was far larger than all the other tool configurations. For the bent $\mathrm{C}$, hoe and mixed blade configurations the degree of soil fragmentation was found similar, regardless of speed changes.

\subsection{Furrow backfill}

A comparison of the furrow backfill was shown in Figure 8 . For all blade configurations, increased rotary speed led to more soil out of the furrow and reduced furrow backfill.

\subsection{Torque and specific work requirement}

The torque requirement for each configuration and speed was shown in Figure 9. The torque was measured to be reduced with increased speed, irrespective of blade configurations. The straight blades had a much higher torque requirement than the other three blade configurations which all had similar torque requirements for each speed.

A comparison of the specific work requirement for each test condition was shown in Figure 10, showing increased specific work with respect to speed. 


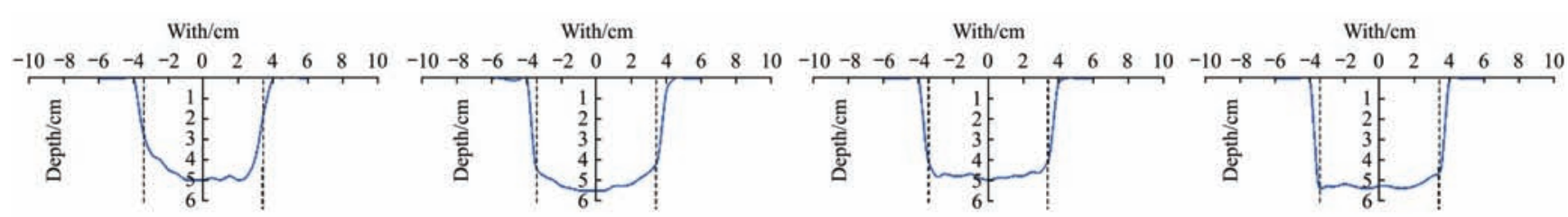

Bent $\mathrm{C}$ blade configuration
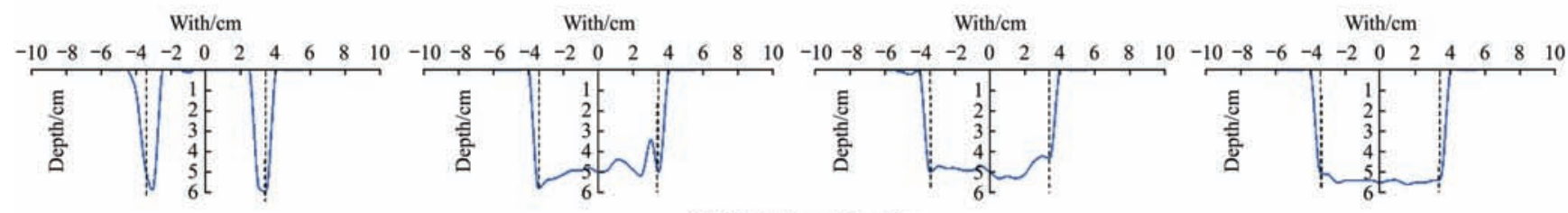

Straight blade configuration

With/cm

With/cm

With/cm

With/cm
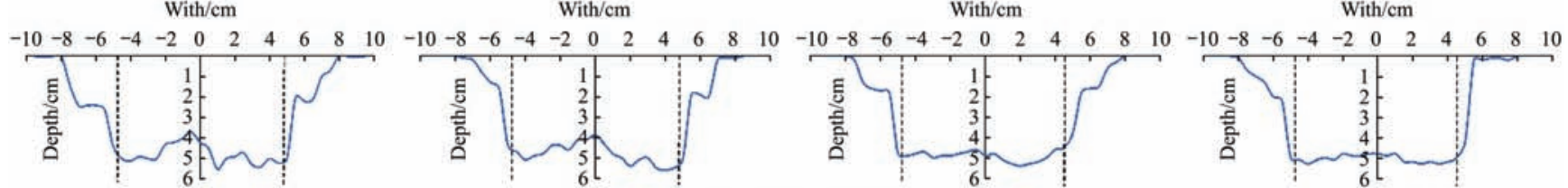

Hoe blade configuration
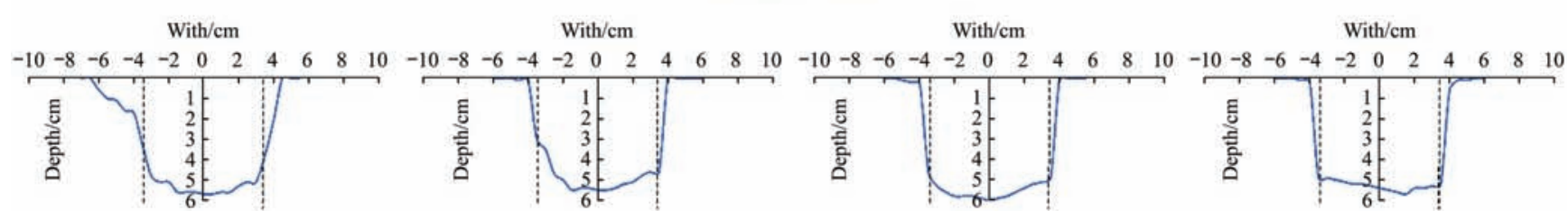

Mixed blade configuration

Figure 4 Effects of blade geometries and rotary speeds on the maximum furrow cross-sectional shapes (left to right: $180 \mathrm{r} / \mathrm{min}, 280 \mathrm{r} / \mathrm{min}, 380 \mathrm{r} / \mathrm{min}$ and $510 \mathrm{r} / \mathrm{min}$ )

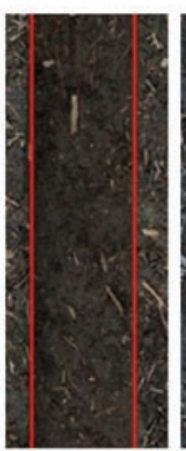

a

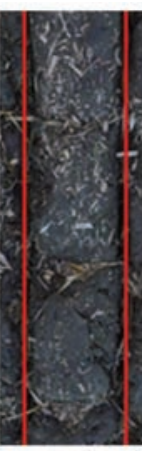

b

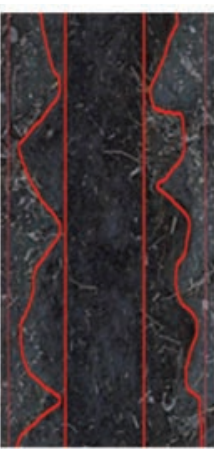

c

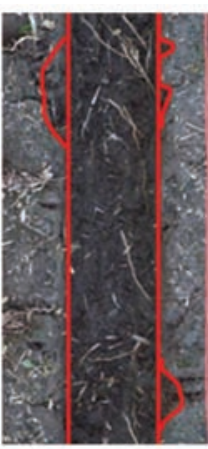

d

Note: a-d: bent $\mathrm{C}$, straight, hoe and mixed blade configurations.

Figure 5 Furrows produced by different configurations at $180 \mathrm{r} / \mathrm{min}$

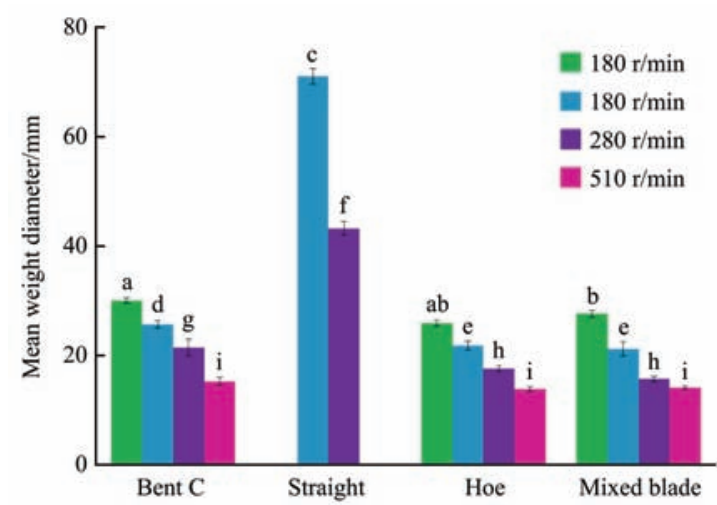

Note: Different normal letters from $\mathrm{a}$ and $\mathrm{b}$ indicate significant difference among blades at $180 \mathrm{r} / \mathrm{min}$; $\mathrm{c}$ to e indicate significant difference among blades at $280 \mathrm{r} / \mathrm{min}$; $\mathrm{f}$ to $\mathrm{h}$ indicate significant difference among blades at $380 \mathrm{r} / \mathrm{min} ; i$ indicates significant difference among blades at $510 \mathrm{r} / \mathrm{min}$.

Figure 7 Effects of blade geometry and rotary speed on MWD

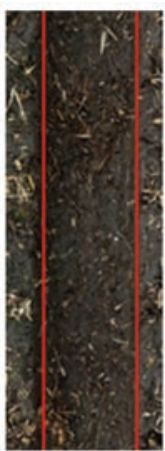

a

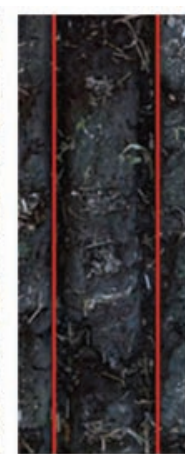

b

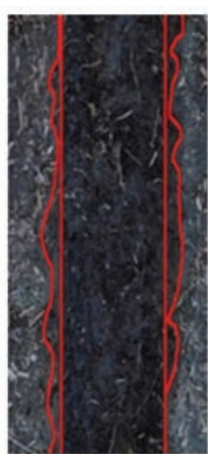

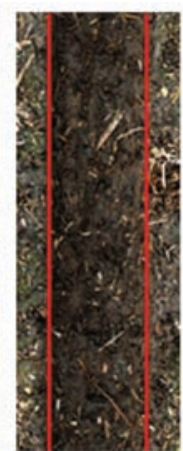

d
Note: a-d: bent $\mathrm{C}$, straight, hoe and mixed blade configurations.

Figure 6 Furrows produced by different configurations at $510 \mathrm{r} / \mathrm{min}$

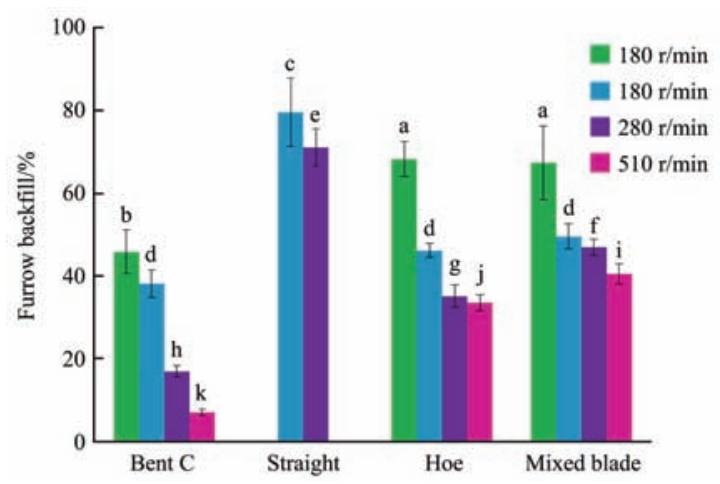

Note: Different normal letters from a and $\mathrm{b}$ indicate significant difference among blades at $180 \mathrm{r} / \mathrm{min}$; c and d indicate significant difference among blades at $280 \mathrm{r} / \mathrm{min}$; e to $\mathrm{h}$ indicate significant difference among blades at $380 \mathrm{r} / \mathrm{min}$; i to k indicate significant difference among blades at $510 \mathrm{r} / \mathrm{min}$.

Figure 8 Effects of blade geometry and rotary speed on furrow backfill 


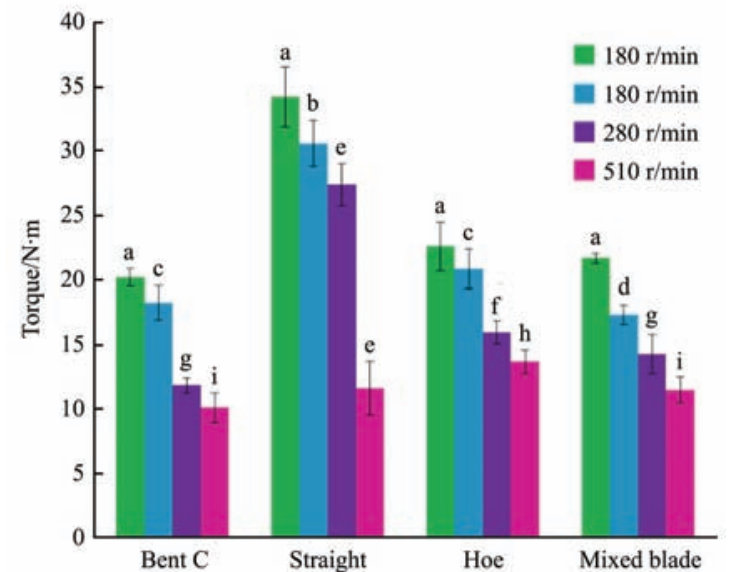

Note: Letter a indicates significant difference among blades at $180 \mathrm{r} / \mathrm{min}$; $\mathrm{b}$ to $\mathrm{d}$ indicate significant difference among blades at $280 \mathrm{r} / \mathrm{min}$; e to $\mathrm{g}$ indicate significant difference among blades at $380 \mathrm{r} / \mathrm{min} ; h$ and $i$ indicate significant difference among blades at $510 \mathrm{r} / \mathrm{min}$.

Figure 9 Effects of blade geometry and rotary speed on torque

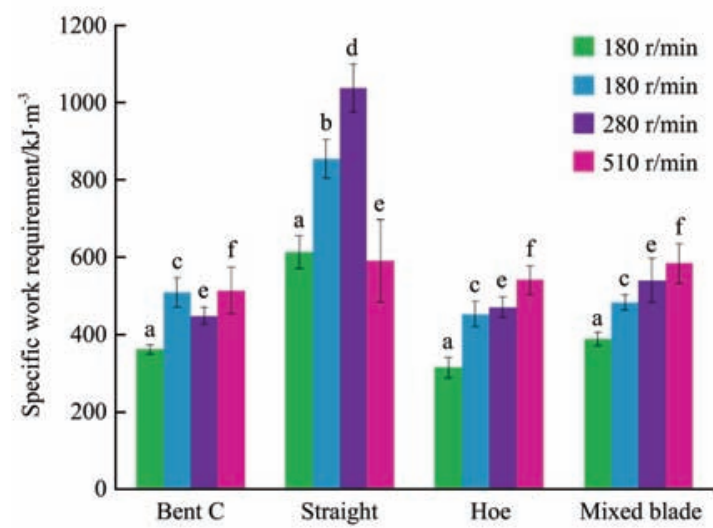

Note: Letter a indicates significant difference among blades at $180 \mathrm{r} / \mathrm{min}$; b and c indicate significant difference among blades at $280 \mathrm{r} / \mathrm{min}$; $\mathrm{d}$ and e indicate significant difference among blades at $380 \mathrm{r} / \mathrm{min}$; $\mathrm{f}$ indicates significant difference among blades at $510 \mathrm{r} / \mathrm{min}$.

Figure 10 Effects of blade geometry and rotary speed on specific work requirement

\section{Discussion}

\subsection{Rotor speed}

For a constant travel speed the bite length of a rotating blade reduces as rotor speed increases. As shown in Figures 4-6, the furrow became more uniform with smaller bite length and taking smaller cuts into the soil. The smaller bite length also explains the lower torque requirement of Figure 9 with increasing speed. The torque per cut reduced with speed, whilst the number of cuts per unit time increased. Therefore the trend of increasing specific work requirement was induced by the increasing speed (Figure 10). This field result was in good agreement with the work reported by Kheiralla et al. ${ }^{[32]}$, Asl et al. ${ }^{[33]}$ and Chertkiattipol et al. ${ }^{[34]}$.

Increasing speed was also observed to result in a finer tilth (lower MWD) for each blade configuration as shown in Figure 7. There are two factors that resulted into this trend. Firstly, the smaller bite length induces smaller clods. Secondly, the higher speed blades throw the soil faster and further, thus resulting in a finer tilth as they are broken more with the higher energy impacts with the shield. Increasing speed resulted in reduced furrow backfill (Figure 8 ) as the blades threw more soil out of the furrow. This agrees with the results that have been reported by Lee et al. ${ }^{[16]}$ and Matin et al. ${ }^{[13]}$.

\subsection{Rotary blade configuration and soil-engaging process}

As the rotary tilling action was a composite result from soil cutting, shearing, re-tills, pulverization and soil throwing, identifying soil failure patterns with visual observation was not possible ${ }^{[35]}$. Altra-low speed simulation in soil bin was made to help understand the actions of the different blade configurations. Figure 11a revealed a soil cutting and shearing failure being induced by the bent $\mathrm{C}$ blades along its cutting edge. The compressing and shearing action induced by the bent $\mathrm{C}$ blades can result into unwanted smearing and compaction on tilled block (Figure 12), leading to reduced soil porosity and impeded gas and water movement ${ }^{[18,36]}$. As the cutting, lifting and carrying were the primary features of the bent $\mathrm{C}$ blade tillage process, a uniform furrow profile was induced as shown in Figures 4, 5a and 6 a. Instead, the lowest furrow backfill was produced by the lifting and throwing the loosened soil out of the furrow. Thus the bent $\mathrm{C}$ blade configuration would not be suitable for seeding.

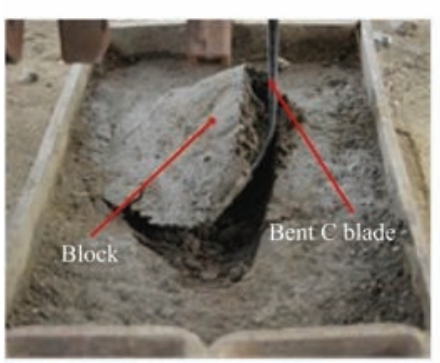

a

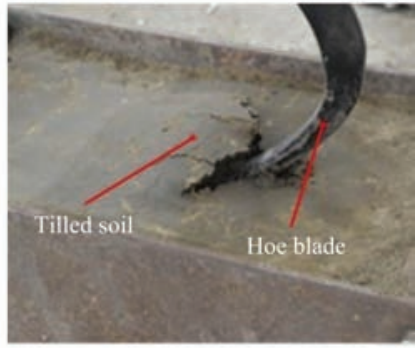

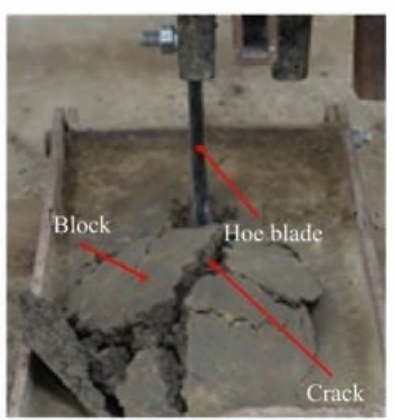

Figure 11 Schematic of induced soil failure by bent $\mathrm{C}$ and hoe blade

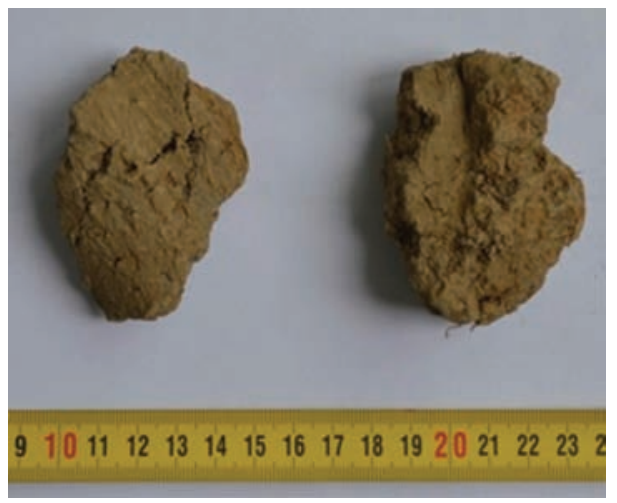

Figure 12 Typical block produced by bent C (left) and hoe blades (right)

The straight blade was observed to act like a narrow tine passing through the paddy soil (Figures $5 \mathrm{~b}$ and $6 \mathrm{~b}$ ). At the low rotary speed of $180 \mathrm{r} / \mathrm{min}$, each straight blade cut a narrow seed furrow in the soil without inducing enough lateral stress on the contacting surface to fracture the soil between the seed furrows to create a loosened furrow suitable for seeding. As the speed increased to $280 \mathrm{r} / \mathrm{min}$ and $380 \mathrm{r} / \mathrm{min}$, the lateral stress on the soil 
was sufficient to fracture between the seed furrows to create a loosened furrow. Since there was no direct cutting of the soil between the blades, and also the blades were incapable of lifting and throwing the soil into the shield (other than by friction and adhesion), the clods of soil in the furrow were very large (Figure 7) and less suitable for seeding. The largest torque and energy demand was induced at the rotary speed lower than $380 \mathrm{r} / \mathrm{min}$, and this result was similar with the disc type strip-tillage tool proposed by Lee et al. ${ }^{[16]}$. However, again at $510 \mathrm{r} / \mathrm{min}$ the furrow was not fully formed, which may attribute to the short period of blade-soil contact. Instantaneous blade-soil contact does not allow enough adhesion between the tool and the soil, leading to the failure of producing a continuous furrow. Insufficient adhesion could be another account for the reduced torque at $510 \mathrm{r} / \mathrm{min}$ as shown in Figure 9. As furrow formation could not be guaranteed for all speeds and the resulting tilth was not fine enough, this blade configuration would not be suitable for seeding.

Ultra-low speed simulation revealed that the soil-engaging process of the hoe blade was composed of two stages, i.e. tool penetration into the soil (Figure 11b) and tensile failure of the soil by the tool lifting (Figure 11c). In the tensile failure stage the soil splits ahead of the cutting edge of the blade and a number of stochastic cracks rapidly extend, separating the soil into multiple clods. This observation was in good agreement with the work reported by Aluko et al. ${ }^{[25]}$ The beneficial tensile failure induced by the hoe blade is good for soil structures. As shown in Figure 12, the hoe blade thus induced a localized compressing and smearing surface on the clod, leaving the remained larger tensile failure surface undamaged by the tool actions. However, the randomized tensile cracks lack confinement and worsened the furrow shape uniformity, even in higher speeds (Figure 7). Therefore, even with a good soil structure and satisfactory furrow backfill (Figure 8), and the hoe blade configuration would also not be suitable for seeding.

The mixed blade configuration provided an improved uniformity of furrow shapes than the hoe blade configuration and a reduced smearing both on the tilth and the furrow boundaries than the bent $\mathrm{C}$ blades. The straight blades aside cut through the soil and formed a straight furrow side wall. The hoe blade immediately following the straight blade induced a parabolic failure boundary which extends to the rear of the finished furrow wall processed by the straight blade. Soil fragmentation by the mixed blade configuration was comparable to that of the four-blade bent $\mathrm{C}$ and hoe blade configurations (Figure 7), even though only 2 hoe type blades were used. The soil loosened by the hoe-type blades with a tendency of sideways movement was effectively intercepted by the following straight blade, a principle similar with the optimized mechanism of soil-tool interaction using straight blades which was proposed by Matin et al. ${ }^{[13]}$ and Lee et al. ${ }^{[16]}$. Significance difference analysis revealed that, for speeds higher above $280 \mathrm{r} / \mathrm{min}$, the mixed blades configuration provided the highest furrow backfill (Figure 8). Unlike the simultaneous soil cutting with double discs proposed by Lee et al. ${ }^{[16]}$, the intertwined arrangement of the straight and hoe blade facilitated a sequenced soil cutting on the boundaries and the within furrow soil, facilitating an alternative relieving of boundary constraints. Thus the mixed blades design reduced the torque and energy demand as compared with the straight and hoe blade configurations (Figures 9 and 10).

Considering the furrow shape requirement, the soil structural quality and the energy demand, the in-situ field experiment proved that the mixed blade configuration was an optimized tool design for strip-tillage in the rice-wheat rotation.

\section{Conclusions}

Experimental results of four blade configurations operating at four speeds for a rotary tiller operating in a paddy soil revealed that a strip-tillage furrow suitable for a seedbed could be produced under certain conditions. Using the bent $\mathrm{C}$ blades resulted in a fine fragmentation but too much soil was thrown out of the furrow and the soil was smeared too much for it to be a suitable tool for preparing a seedbed. The straight blades on their own could not cut a continuous furrow at 180 or $510 \mathrm{r} / \mathrm{min}$ and even when it did cut a furrow at 280 and $380 \mathrm{r} / \mathrm{min}$ the tilth was too coarse to be suitable for a seedbed. The hoe blades alone produced a good soil structure, but a uniform shape of furrow was not possible.

This study recommends the use of a mixed tool configurations made up of a pair of central hoe blades with a pair of straight blades on each side at a spacing of $65 \mathrm{~mm}$ operating at a speed between $280 \mathrm{r} / \mathrm{min}$ and $380 \mathrm{r} / \mathrm{min}$. With this configuration the loosening ability of the hoe type blade was combined with the soil entrapment and furrow wall cutting of the straight blades. Hence, this configuration had lower torque and specific work requirement whilst achieving a suitable tilth (good tillage-induced soil structure with low MWD) and good furrow backfill. Further work is recommended to evaluate this proposed configuration in a range of straw mulching and cropping situations.

\section{Acknowledgements}

The authors gratefully acknowledge that this research was financially supported by the State Key Program of China (2016 YFD 0300900) and Jiangsu Agri. Mech. Fund (201-051028). The assistance from our lab mates and teachers were also acknowledged.

\section{[References]}

[1] Timsina J, Connor D J. Productivity and management of rice-wheat cropping systems: issues and challenges. Field Crops Research, 2001; 69(2): 93-132.

[2] Muhammad F, Shahzad B M A, Asad Saeed A. Comparison of conventional puddling and dry tillage in rice-wheat system. Paddy \& Water Environment, 2008; 6(4): 397-404.

[3] Olaf E, Vijay L. Zero tillage impacts in India's rice-wheat systems: A review. Soil \& Tillage Research, 2008; 100(1-2): 1-14.

[4] Mubarik A, Derek B. Productivity Growth and Resource Degradation in Pakistan's Punjab: A Decomposition Analysis. Economic Development \& Cultural Change, 2000; 423(50): 839-863.

[5] Scott D, Daniel M, Paul H, David C. Soil aggregates and associated organic matter under conventional tillage, no-tillage, and forest succession after three decades. Plos One, 2014; 9(1): 482-498.

[6] Fiaz A, Ding W M, Ding Q S, Mubshar H, Khawar J. Forces and straw cutting performance of double disc furrow opener in no-till paddy soil. Plos One, 2015; 10(3).

[7] Bianchini A, Magalhães P S G. Evaluation of coulters for cutting sugar cane residue in a soil bin. Biosystems Engineering, 2008; 100(3): 370-375.

[8] Muhammad F, Ahmad N. Weed dynamics and productivity of wheat in conventional and conservation rice-based cropping systems. Soil and Tillage Research, 2014; 141: 1-9.

[9] Blevins R L, Frye W W. Conservation tillage: An ecological approach to soil management. Advances in Agronomy, 1993; 51: 33-78.

[10] [10] Licht M A, Mahdi A. Strip-tillage effect on seedbed soil temperature and other soil physical properties. Soil and Tillage Research, 2005; 80(1-2): 233-249.

[11] Berntsen R, Berre B. Soil fragmentation and the efficiency of tillage implements. Soil \& Tillage Research, 2002; 64(1): 137-147.

[12] Abbaspour-Gilandeh Y, Sharabiani V R, Khalilian A. Effects of tillage 
methods on soil fragmentation in loamy-clay soils. American Journal of Agricultural \& Biological Science, 2009; 4(2): 131-136.

[13] Matin M A, Fielke J M., Desbiolles J M A. Furrow parameters in rotary strip-tillage: Effect of blade geometry and rotary speed. Biosystems Engineering, 2014; 118(1): 7-15.

[14] Targio H I A, Ibrar Y, Badrul A N, Salimah M, Abdullah G, Samee U K. The rise of "big data" on cloud computing: Review and open research issues. Information Systems, 2015; 47: 98-115.

[15] Baker C J, Saxton K E, Ritchie W R, Chamen W C T, Reicosky D C, Ribeiro M F S, et al. No-tillage seeding in conservation agriculture. Second Edition, London, UK. Food and Agriculture Organization of the United Nations, 2006

[16] Lee K S, Park S H, Park W Y, Lee C S. Strip tillage characteristics of rotary tiller blades for use in a dryland direct rice seeder. Soil and Tillage Research, 2003; 71(1): 25-32.

[17] Matin M A, Fielke J M, Desbiolles J M A. Torque and energy characteristics for strip-tillage cultivation when cutting furrows using three designs of rotary blade. Biosystems Engineering, 2015; 129: 329-340.

[18] Matin M A, Desbiolles J M A, Fielke J M. Strip-tillage using rotating straight blades: Effect of cutting edge geometry on furrow parameters. Soil and Tillage Research, 2016; 155: 271-279.

[19] Tagar A A, Ji C Y, Jan A, Julien M, Chen S Q, Ding Q S, et al. Finite element simulation of soil failure patterns under soil bin and field testing conditions. Soil \& Tillage Research, 2015; 145: 157-170.

[20] Rosa U A, Wulfsohn D. Soil bin monorail for high-speed testing of narrow tillage tools. Biosystems Engineering, 2008; 99(3): 444-454.

[21] Dexter A R, Bird N R A. Methods for predicting the optimum and the range of soil water contents for tillage based on the water retention curve. Soil \& Tillage Research, 2001; 57(4): 203-212.

[22] Edward M, Desir F L. Prediction and field measurements of tillage tool draft forces and efficiency in cohesive soils. Soil \& Tillage Research, 1984; 4(5): 459-470.

[23] Alavi N, Hojati R. Modeling the soil cutting process in rotary tillers using finite element method. International Journal of Agriculture Research, 2012; 8(1): 27-37.

[24] Tagar A A, Ji C Y, Ding Q S, Jan A, Chandio F A, Mari I A. Soil failure patterns and draft as influenced by consistency limits: An evaluation of the remolded soil cutting test. Soil \& Tillage Research, 2014; 137(4): 58-66.

[25] Aluko O B, Seig D A. An experimental investigation of the characteristics of and conditions for brittle fracture in two-dimensional soil cutting. Soil and Tillage Research, 2000; 57(3): 143-157.

[26] John B G. The hydrometer as a new method for the mechanical analysis of soils. Soil Science, 1927; 23(5): 343-353.

[27] Chen Y, Munkholm L J, Tavs N. A discrete element model for soil-sweep interaction in three different soils. Soil \& Tillage Research, 2013; 126(1): 34-41.

[28] Dexter A R, Birkas M. Prediction of the soil structures produced by tillage. Soil and Tillage Research, 2004; 79(2): 233-238.

[29] Johan A, Olof H. Specific draught, soil fragmentation and straw incorporation for different tine and share types. Soil and Tillage Research, 2010; 110(1): 154-160.

[30] Caruso T, Barto E K, Siddiky M R K, Smigelski J, Rillig M C. Are power laws that estimate fractal dimension a good descriptor of soil structure and its link to soil biological properties? Soil Biology and Biochemistry, 2011; 43(2): 359-366.

[31] Ondrej P, Andjelko B, Aleksandra D, Lazar S, Milan T, Mirko S, et al. The effects of working parameters and tillage quality on rotary tiller specific work requirement. African Journal of Agricultural Research, 2011; 6(31): 6513-6524.

[32] Kheiralla A F, Azmi Y, Zohadie M, Ishak W. Modelling of power and energy requirements for tillage implements operating in Serdang sandy clay loam, Malaysia. Soil and Tillage Research, 2004; 78(1): 21-34.

[33] Habibi A J, Surendra S. Optimization and evaluation of rotary tiller blades: Computer solution of mathematical relations. Soil and Tillage Research, 2009; 106(1): 1-7.

[34] Chertkiattipol S, Niyamapa T. Variations of torque and specific tilling energy for different rotary blades. International Agricultural Engineering Journal, 2010; 19(3): 1-14.

[35] Takashi K, Sakae S. Soil-blade dynamics in reverse- rotational rotary tillage. Journal of Terramechanics, 2002; 39(2): 95-113.

[36] Johansen C, Haque M E, Bell R W, Thierfelder C, Esdaile R J. Conservation agriculture for small holder rainfed farming: Opportunities and constraints of new mechanized seeding systems. Field Crops Research, 2012; 132: 18-32. 